\author{
Jun/2020 \\ Working Paper 20-18 \\ rcea.org/RePEc/pdf/wp20-18.pdf
}

\title{
INSURABLE LOSSES, PRE-FILLED CLAIMS FORMS AND HONESTY IN REPORTING
}

\author{
William G. Morrison \\ Wilfrid Laurier University, Canada \\ Bradley J. Ruffle \\ McMaster University, Canada \\ RCEA
}

Copyright belongs to the author. Short sections of the text, not exceeding three paragraphs, can be used provided proper acknowledgement is given.

The Rimini Centre for Economic Analysis (RCEA) was established in March 2007. RCEA is a private, nonprofit organization dedicated to independent research in Applied and Theoretical Economics and related fields. RCEA organizes seminars and workshops, sponsors a general interest journal, the Review of Economic Analysis (REA), and organizes a biennial conference, the Rimini Conference in Economics and Finance (RCEF). Scientific work contributed by the RCEA Scholars is published in the RCEA Working Paper series.

The views expressed in this paper are those of the authors. No responsibility for them should be attributed to the Rimini Centre for Economic Analysis. 
INSURABLE LOSSES, PRE-FILLED CLAIMS FORMS AND HONESTY IN REPORTING

\author{
William G. Morrison \\ Department of Economics \\ Wilfrid Laurier University \\ Waterloo, Ontario, Canada \\ Bradley J. Ruffle \\ Department of Economics \\ McMaster University \\ Hamilton, Ontario, Canada
}

June 2020

\begin{abstract}
We design a series of laboratory experiments to investigate the effects of purchasing insurance and of pre-filled claim forms on dishonesty in loss reporting. In our experiment, participants report the outcome of privately rolling two dice where the numbers rolled map to a payoff distribution with the possibility of losses in earned income. Prior to this reporting task, participants bid for a limited number of insurance contracts which issue an indemnity payment equal to each insured individual's reported loss. We find that dishonest reporting is significantly more prevalent among insured individuals relative to the uninsured, consistent with an 'entitlement bias'. Further we find that prefilling the reporting form with the most probable outcome only modestly constrains dishonest reporting among both insured and uninsured individuals. We explore reasons why prefilled forms should be applied with caution.
\end{abstract}

Keywords: experimental economics, pre-filled forms, pre-populated fields, insurance, dishonesty, claim build-up.

JEL codes: C91, D82, G22. 


\section{Declarations}

Funding:

Funding for this research was provided by the Lazaridis Institute for the Management of Technology Enterprises

Conflicts of interest/Competing interests:

There are no conflicts of interest

Availability of data and material:

Upon request, data from this study will be made available.

Authors' contributions

All authors contributed to the study conception and design, material preparation, data collection and analysis and the writing of the manuscript. 


\section{Introduction}

We report on a series of laboratory experiments designed to study honesty in reporting losses resulting from an insurable risky event. We utilize an innovative protocol to examine the effect of a pre-populated field in an online reporting form on the reporting of unverifiable individual losses. We find that cheating is more prevalent among the insured than the uninsured. Additional analyses, a reporting treatment in which insurance is unavailable for purchase and a post-experiment question suggest that this is the result of an 'entitlement bias' among the insured, rather than loss aversion, risk preferences or a selection effect. Pre-filled claim amounts have a limited effect on restraining dishonest reporting. We discuss a number of reasons why this is the case.

\section{Motivation}

Asymmetric information characterizes the insurance industry - only customers know the true value of losses they claim for reimbursement. Opportunistic clients can exploit this information asymmetry to either make fraudulent claims or to exaggerate the magnitude of damages associated with legitimate claims. The extent of this latter type of opportunistic fraud, sometimes referred to as 'claim buildup' in the insurance industry, is not something that insurance companies go out of their way to make public and consequently accurate publicly available estimates are hard to find. However, a Canadian study in 2001 found that opportunistic fraud was present in 34\% of accident benefit claims and 26\% of bodily injury claims (Canadian Underwriter, 2001). The study estimated the total cost of accident benefit and bodily injury fraud to be $15-22 \%$ of all paid losses for private insurers in Canada; approximately $\$ 1.3$ billion CAN annually. In the USA, it is estimated that insurance fraud costs insurers (and ultimately consumers through higher premiums) approximately $\$ 80$ billion a year (FBI, 2019; Ensure.com, 2015). While a sizable portion of this total is likely the result of 'hard' insurance fraud by organized crime, a significant portion also comes from 'soft' fraud including exaggerated claims. Moreover, there are indications that while insurance clients may disapprove of those intent on committing hard fraud, they are more tolerant of soft fraud and in some cases find such activities acceptable. For example, almost a quarter of survey respondents thought it was acceptable to inflate an insurance claim in order to offset the expense of a deductible (Insurance Research Council, 2013). More generally, a problem faced by all insurers is client feelings of entitlement when making a claim, based on a perception that premium payments (perhaps having been made over a long period of time without any claim) represent a form of 
investment rather than a payment for risk-pooling and that they are entitled to a return on this investment. Such feelings of entitlement help to motivate a willingness to inflate legitimate claims.

Meanwhile, due to advances in digital technology and data analytics, insurance companies know an ever-increasing amount of information about their clients and the value of their insurance claims without the need to ask. For example, in the event of a flood in a given geographical area, an insurer can pool and cross tabulate data from multiple claims to generate a distribution of claim amounts that take into account the geographical differences between claim locations. Rumson and Hallet (2019) report that insurers now have access to vast amounts of Earth Observation data from a new generation of satellites at increasingly lower cost. They argue that this data can be combined with claims data to provide new insights into flood damages and to validate outcomes. Given that a growing number of insurance customers communicate with their insurance provider online, the possibility exists for insurance companies to present clients with pre-populated fields in online claims forms, including the claim amount. Pre-filled fields not only simplify and expedite the claims process, but they may also be used to influence reporting behavior, in particular, to restrain fraudulent or inflated claims.

\section{Related Literature}

Economic analysis of an entitlement bias per se is scarce. Several bargaining-game studies manipulate the sense of entitlement of the parties involved by having the Allocators (Hoffman and Spitzer 1985; Hoffman et al. 1994; Cherry et al. 2002) or the Responders (Ruffle 1998; GarciaGallego et al. 2008) earn the surplus over which subsequent negotiations take place. Mazar et al. (2008) posit a theory of self-concept maintenance in which individual actions that are malleable in their categorization enable individuals to engage in dishonest behavior without changing their own self image. Under this theory, individuals may be able to rationalize an inflated insurance claim as justifiably counteracting the insurer's possible discounting of actual damages. McGregor (2008) places claims of entitlement within a broader behavioral theory of neutralization wherein individuals seek defence mechanisms that allow them to downplay the repercussions of their actions on others. A claim of entitlement justifies actions otherwise viewed as inappropriate or illegal on the basis that the individual somehow deserves the outcome of the behavior. McGregor (2008) argues that under neutralization theory claims of entitlement may be combined with claims of relative acceptability (claims build-up is on a very small scale in comparison to premeditated 
acts of criminal fraud) and beliefs regarding social norms ('everyone else inflates their claims'). In the context of insurance, Conners and Feldblum (1998, p.380) describe an 'entitlement philosophy’ motivating claims buildup as follows:

"Many accident victims, having paid thousands of dollars over the years for their auto insurance, now feel that they are entitled to recover their money from the "insurance industry."

In an experimental study of insurance claims, von Bieberstein and Schiller (2018) examine reporting behavior in a mutual insurance setup such that insurance premiums are paid to, and claims are paid from, a group account. They find that insurance contracts with a deductible increase both fraudulent and inflated claims compared to full coverage or bonus-malus contracts (i.e., contracts with no deductible but with premiums that rise or fall conditional on prior claims).

We are unaware of any studies that investigate the influence of pre-filled forms on reporting behavior in an insurance context, however a number of recent papers examine the role of pre-filled values in the context of income-tax returns. Gillitzer and Skov (2018) show that third-party reporting of charitable donations to Denmark's tax authority which is then pre-populated on Danish taxpayers' tax returns doubles the number of taxpayers that claim a charitable deduction and increases the total value of deductions claimed by $15 \%$. The authors attribute the surge in deductions claimed to unclaimed deductions when charitable donations were self-reported. Fonseca and Grimshaw (2018) investigate tax liability reporting in hypothetical scenarios via an online experiment in which fictitious taxpayers are assigned a profile of income and expenses. They find that accurate pre-filled tax liability amounts increase compliance and tax revenues, whereas low (inaccurate) pre-filled values increase tax evasion. Employing a similar methodology, Doxey et al. (2019) use Amazon Mechanical Turk to recruit experienced taxpayers who are presented with hypothetical tax-reporting scenarios. The authors find that pre-filled tax returns without estimates of undocumented income (i.e., cash tips) result in lower compliance rates than self-completed tax returns. However, compliance improves as the pre-filled estimate of undocumented income increases, eventually surpassing that achieved with self-completed returns as the estimate approaches the actual cash income. In van Dijk et al. (2020), subjects reviewed and filed 100 simplified tax returns that differed in whether the tax liability was prefilled and its accuracy. The authors find that accurate prefilled liabilities yielded the highest rate of compliance, followed by unfilled liabilities, then overestimated liabilities, with underestimated liabilities displaying the lowest rates of compliance. Fochmann et al. (2018) design a series of experiments 
in which subjects first earn income at a real-effort task and then report this income for the purpose of paying a $25 \%$ income tax. They find that tax compliance is higher when the pre-filled income field corresponds to the correct amount or to an amount higher than the subject's income than when the income field is blank. At the same time, when the pre-filled income field underestimates the subject's income, compliance levels do not differ from those when the income field is left blank. Lastly, in a context-free experiment, Duncan and Li (2018) design a task in which control group participants self-report the outcome of a six-sided die roll (for which payoffs are increasing in the number rolled, except for the number six which receives a zero payoff). Treatment group participants complete a confirmatory report in which they can either accept a randomly selected pre-filled value between one and six or replace it. Duncan and Li (2018) find that the confirmatory report format increases the number who report rolling a six (with a zero payoff) compared to the self-reporting format. Further, they find that pre-filled values increase honest reporting.

Our experiments focus on honesty in reporting in the context of a risky but insurable event where losses are possible. In our design, the purchase of insurance is voluntary and the reporting format may contain a pre-filled value. Unlike previous studies, our pre-filled values are neither random nor fully informed, but instead reflect partial information (best guess) about each participant's most likely outcome. Our design allows us to test firstly for the presence of an entitlement bias that influences reporting by insured relative to uninsured individuals. Secondly, we test whether pre-filled values in the reporting form lessens dishonesty in reporting. Our results lend support to the existence of an entitlement bias associated with the purchase of insurance which leads to greater dishonesty in reporting. We also find that pre-filled values are limited in their ability to reduce dishonesty in claim reports.

\section{Experimental Design and Procedures}

\subsection{Experimental Design ${ }^{1}$}

\section{Earned endowment and risk preferences elicitation task (Task 1)}

Participants begin the experimental session by completing an online quiz of 12 questions that includes some basic numeracy questions and some basic reading comprehension questions. ${ }^{2}$ The

\footnotetext{
${ }^{1}$ Appendices A and B provide the complete instructions used in the experiment along with screenshots.

${ }^{2}$ For each session, the set of 12 questions in this quiz and the one preceding the reporting task were randomly drawn from a question bank we compiled.
} 
test is designed such that all participants ought to answer 6 or more questions correctly, thereby entitling them to an earned endowment of 300 lab dollars (LD). All LD received by participants are converted into a cash payment at an exchange rate of $100 \mathrm{LD}$ equals \$0.70 Canadian (CAD) at the end of the experimental session. ${ }^{3}$ Participants then complete an incentivized risk-preferenceelicitation task following Gneezy and Potters (1997) in order to provide an index of their willingness to take or avoid risk. Specifically, participants are given the opportunity to invest all, some or none of the 300 LD they earned from completing the quiz (in 30 LD increments) in a lottery with a 50\% chance of success and a 50\% chance of failure. If the investment succeeds, it pays 2.5 times the amount invested. Failure results in the investor losing the amount invested. Whatever portion of the $300 \mathrm{LD}$ is not invested is retained by each participant.

\section{Insurable risk reporting task and insurance market (Task 2)}

Following the risk preference elicitation task (Task 1), subjects are asked to compete a second online quiz with numeracy and reading comprehension questions. Successfully answering six or more questions correctly out of 12 results in earnings of 1500 LD which are then placed at risk in our main 'insurable-risk-reporting' (IRR) task (Task 2). The IRR task has two components: (1) a lottery in which the best possible outcome is no change in LD earnings while other outcomes involve losses and (2) an insurance market in which participants bid on a limited number of insurance contracts each of which offer an indemnity equal to an individual's reported loss amount.

Participants are informed that they will be asked to roll two dice in private and report the sum of the two numbers rolled (referred to as the 'outcome') in a reporting form on the computer screen. Participants are then told that each die outcome corresponds to one of three possible payoffs: zero (no change), -500 ( a loss of 500 LD) or -1000 (a loss of 1000 LD). Participants are then shown one of two possible mappings of die outcomes to payoffs. In one treatment, the correspondence of dice outcomes to monetary payoffs is heavily concentrated on -500 LD: the probability of rolling an outcome associated with that payoff is 0.83 while the probability of rolling an outcome associated with either $0 \mathrm{LD}$ or $-1000 \mathrm{LD}$ is 0.083 . We term this the 'low information asymmetry' (LO) treatment. In contrast the probability density function in our 'high information asymmetry' (HI) treatment is flatter with the probability of an outcome associated a payoff of -

\footnotetext{
${ }^{3}$ At the time we conducted these experiments, \$1 CAD equaled \$0.75 USD or $0.66 €$.
} 
$500 \mathrm{LD}$ equal to 0.44 while the probability of either $0 \mathrm{LD}$ or $-1000 \mathrm{LD}$ is equal to 0.278 . In each case, the expected payoff is $-500 \mathrm{LD}$, however a guess that an individual's realized payoff is -500 $\mathrm{LD}$ will be correct more often in the $\mathrm{LO}$ treatment. These mappings of die outcomes to payoffs are summarized below in Table 1 .

Table 1: Payoff assignments and probabilities

\begin{tabular}{|c|c|c|c|c|c|c|}
\hline \multirow{2}{*}{ Payoff } & \multicolumn{3}{|c|}{ Low Information Asymmetry } & \multicolumn{3}{c|}{ High Information Asymmetry } \\
\cline { 2 - 7 } & Dice Outcomes & Fraction & Prob. & Dice Outcomes & Fraction & Prob. \\
\hline 0 & 11,12 & $3 / 36$ & 0.083 & $9,10,11,12$ & $10 / 36$ & 0.278 \\
\hline-500 & $4,5,6,7,8,9,10$ & $30 / 36$ & 0.833 & $6,7,8$ & $16 / 36$ & 0.444 \\
\hline-1000 & 2,3 & $3 / 36$ & 0.083 & $2,3,4,5$ & $10 / 36$ & 0.278 \\
\hline
\end{tabular}

The insurance market

After the IRR task has been explained but before its implementation, participants are offered the chance to purchase insurance using their 1500 LD earnings. Any participant who succeeds in purchasing insurance has the premium deducted from their $1500 \mathrm{LD}$ balance and in return will be fully reimbursed for any feasible losses they report.

Rather than sell insurance to those who wish to buy it at a fixed premium, we elected instead to sell it via a uniform $n+1$ price auction in which each of the $2 n$ participants in a session simultaneously submits a sealed bid for the purchase of an insurance policy. The sale of insurance policies through an auction requires participants to think about how insurance works in order to formulate a bid and provides us with each participant's precise willingness to pay for insurance. In our auction mechanism, the $n$ participants who submit the highest bids all pay a uniform premium equal to the $(n+1)^{\text {th }}$ highest bid. This is the multi-unit equivalent of the Vickrey (1961) uniform second-price, sealed-bid auction in which bidding one's reservation price is the unique equilibrium strategy. In terms of our design, the sale of $n$ policies to $2 n$ participants guarantees that our sample is equally divided into those who purchase insurance and those who do not and alleviates the need to exogenously determine the insurance premium that achieves this balance. All of our experimental sessions with an insurance auction consisted of groups of eight participants so that the four highest bidders for insurance received a policy and each paid a uniform price equal to the fifth highest bid. 
To summarize the determination of participant $i$ 's payoff in group $j$, insured subjects earn their endowment of 1500 LD plus their reported outcome minus the price of the insurance, whereas uninsured subjects earn their $1500 \mathrm{LD}$ endowment minus their reported outcome. That is,

$$
\pi_{i, j}= \begin{cases}1500+\text { report }_{i}-\text { premium }_{j} & \text { if insured } \\ 1000-\text { report }_{i} & \text { if uninsured. }\end{cases}
$$

The value placed on an insurance contract may depend on the participant's type with respect to honesty. For a maximally honest participant (who always reports the true die outcome), the expected value of insurance is twice the mean of the payment distribution because an insured individual receives this value in expectation while an uninsured individual pays this value in expectation. For our chosen parameters, a maximally honest participant values insurance at 1000 LD. A maximally dishonest participant with insurance will report the largest loss in the payment distribution and when uninsured will report the smallest loss in the distribution. Thus, to a maximally dishonest individual, the value of insurance equals $\sup (f(x))-\inf (f(x))$, where $f(x)$ represents the payoff distribution. Consequently, given our chosen parameters, maximally dishonest participants also value insurance at $1000 \mathrm{LD}$.

Once the insurance auction has been completed, participants are instructed to role the two die in private at their station and to report both the die outcome (i.e., sum of the two numbers rolled) and the payoff assigned to that outcome.

Figure 1: Experimental design overview

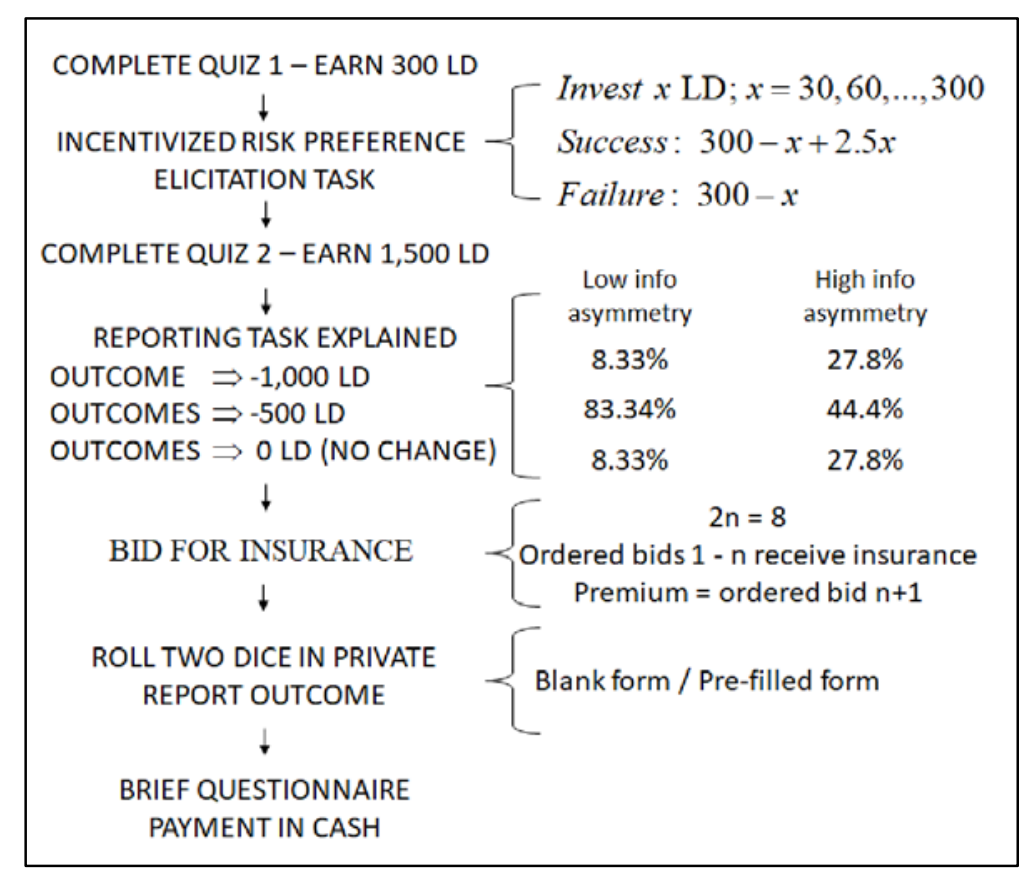


The on-screen reporting form for recording this event is either blank or is pre-filled with the most likely payoff (-500 LD). We thus have a partial 2x2x2 experimental design to examine the influence of three variables on participants’ reporting decisions; 1) insured versus uninsured participants, 2) high- versus low-information asymmetry between participants and the experimenter and 3) a pre-filled versus a blank reporting field. Figure 1 provides an overview of the entire design.

\subsection{Experimental Procedures}

The experiment was programmed using oTree (Chen et al. 2016) and about three-quarters of our experimental sessions overall and in each treatment were conducted at Wilfrid Laurier University with the remaining quarter held at McMaster University. The recruitment software restricted participation to one session per individual. In total, 357 individuals participated in our experiments: 272 participated in our main sessions, and an additional 85 participants participated in noinsurance treatments (to be discussed later). Table 2 summarizes all our treatments in the main experiment.

Table 2: Experimental treatments and insurance outcomes

\begin{tabular}{|l|c|c|c|}
\hline Reporting form & $\begin{array}{c}\text { Information } \\
\text { Asymmetry }\end{array}$ & $\begin{array}{c}\text { Purchased } \\
\text { Insurance }\end{array}$ & Participants \\
\hline BLANK & HI & Yes & 40 \\
\hline BLANK & HI & No & 40 \\
\hline PREFILL & HI & Yes & 40 \\
\hline PREFILL & HI & No & 28 \\
\hline BLANK & LO & Yes & 28 \\
\hline BLANK & LO & No & 28 \\
\hline PREFILL & LO & Yes & 28 \\
\hline PREFILL & LO & No & 28 \\
\hline
\end{tabular}

At the beginning of each session, printed instructions for the first quiz and the riskpreferences elicitation task were distributed and read individually by subjects. An experimenter then read them aloud. Subjects then worked their way through the onscreen instructions, the 12 
quiz questions and the risk-preferences task. ${ }^{4}$ When everyone had completed this latter task, printouts of the instructions for the IRR task were distributed and read individually by participants before being read aloud by an experimenter. Subjects then returned to the onscreen portion to complete the second quiz, the insurance auction and the reporting task. Once both tasks had been completed, participants were prompted to answer a brief post-experiment survey while the experimenters prepared their payments. Participants were paid a \$4 CAD showup fee, plus their earnings from the two quizzes, which were adjusted to reflect any additional earnings or losses resulting from their decisions in the two tasks. The average total payment was \$16.49 CAD. The entire experiment, including the instruction and payment phases, lasted approximately 50 minutes.

\section{Results}

Table 3: Summary statistics for claims reports and insurance bids by treatment

\begin{tabular}{|c|c|c|c|c|c|}
\hline Treatment & $\begin{array}{l}\text { Insurance } \\
\text { Purchased }\end{array}$ & $\begin{array}{l}\text { Mean Report } \\
\text { (Std. Dev.) }\end{array}$ & $\begin{array}{l}\text { \% Report }-500 \\
\text { (Expected) }\end{array}$ & $\begin{array}{l}\text { Mean Bid } \\
\text { (Std. Dev.) }\end{array}$ & Obs. \\
\hline \multirow[t]{2}{*}{ Blank, HI } & Yes & $\begin{array}{l}-800.0 \\
(316.2)\end{array}$ & $\begin{array}{c}25.0 \% \\
(44.4 \%)\end{array}$ & $\begin{array}{l}1067 \\
(267)\end{array}$ & 40 \\
\hline & No & $\begin{array}{c}-250.0 \\
(320.3)\end{array}$ & $\begin{array}{c}35.0 \% \\
(44.4 \%)\end{array}$ & $\begin{array}{c}475 \\
(254)\end{array}$ & 40 \\
\hline \multirow[t]{2}{*}{ Blank, LO } & Yes & $\begin{array}{l}-732.1 \\
(253.9)\end{array}$ & $\begin{array}{c}53.6 \% \\
(83.3 \%)\end{array}$ & $\begin{array}{l}1017 \\
(237)\end{array}$ & 28 \\
\hline & No & $\begin{array}{l}-314.8 \\
(314.6)\end{array}$ & $\begin{array}{c}48.1 \% \\
(83.3 \%)\end{array}$ & $\begin{array}{c}581 \\
(195)\end{array}$ & 27 \\
\hline \multirow[t]{2}{*}{ Prefill, HI } & Yes & $\begin{array}{l}-750.0 \\
(320.3) \\
\end{array}$ & $\begin{array}{c}35.0 \% \\
(44.4 \%) \\
\end{array}$ & $\begin{array}{l}1088 \\
(271) \\
\end{array}$ & 40 \\
\hline & No & $\begin{array}{l}-275.0 \\
(298.5)\end{array}$ & $\begin{array}{c}45.0 \% \\
(44.4 \%)\end{array}$ & $\begin{array}{c}621 \\
(224)\end{array}$ & 40 \\
\hline \multirow[t]{2}{*}{ Prefill, LO } & Yes & $\begin{array}{c}-732.1 \\
(288.1)\end{array}$ & $\begin{array}{c}46.4 \% \\
(83.3 \%)\end{array}$ & $\begin{array}{l}1006 \\
(261)\end{array}$ & 28 \\
\hline & No & $\begin{array}{l}-339.3 \\
(237.8)\end{array}$ & $\begin{array}{c}67.9 \% \\
(83.3 \%)\end{array}$ & $\begin{array}{c}527 \\
(146)\end{array}$ & 28 \\
\hline
\end{tabular}

Table 3 displays the mean report (standard deviation) and the percentage of participants that reported a payoff associated with the die roll of -500 LD (versus the expected percentage if everyone reported truthfully) for each of the eight treatment outcomes, dividing the reported payoffs into insured vs. uninsured; HI vs. LO informational asymmetry and blank vs. pre-filled reporting form groups. What is immediately apparent from Table 3 and the histograms of reported

\footnotetext{
${ }^{4}$ Upon completion of the risk-preference elicitation task, participants were not immediately informed of the outcome of their investment decision but were told that they would receive this information when both tasks had been completed.
} 
dice outcomes in Figures 2 (HI treatments) and 3 (LO treatments) is that many insured and uninsured participants cheated incompletely in a profit-enhancing direction in all treatments. ${ }^{5}$

\section{Dishonesty among the Insured and Uninsured}

In the HI treatments, although the percentage of subjects that reports -500 does not differ significantly from the expected percentage of $44.4 \%$ (indicated by the upper dashed line in Figure 2), the frequencies of reports of 0 and -1000 differ significantly from the expected percentage of 27.8\% (indicated by the lower dashed line in Figure 2) and in a self-serving direction for both insured and uninsured subjects. That is, insured subjects vastly over-report -1000 and under-report 0 relative to the expected frequency, while those without insurance do just the reverse.

\section{Figure 2}

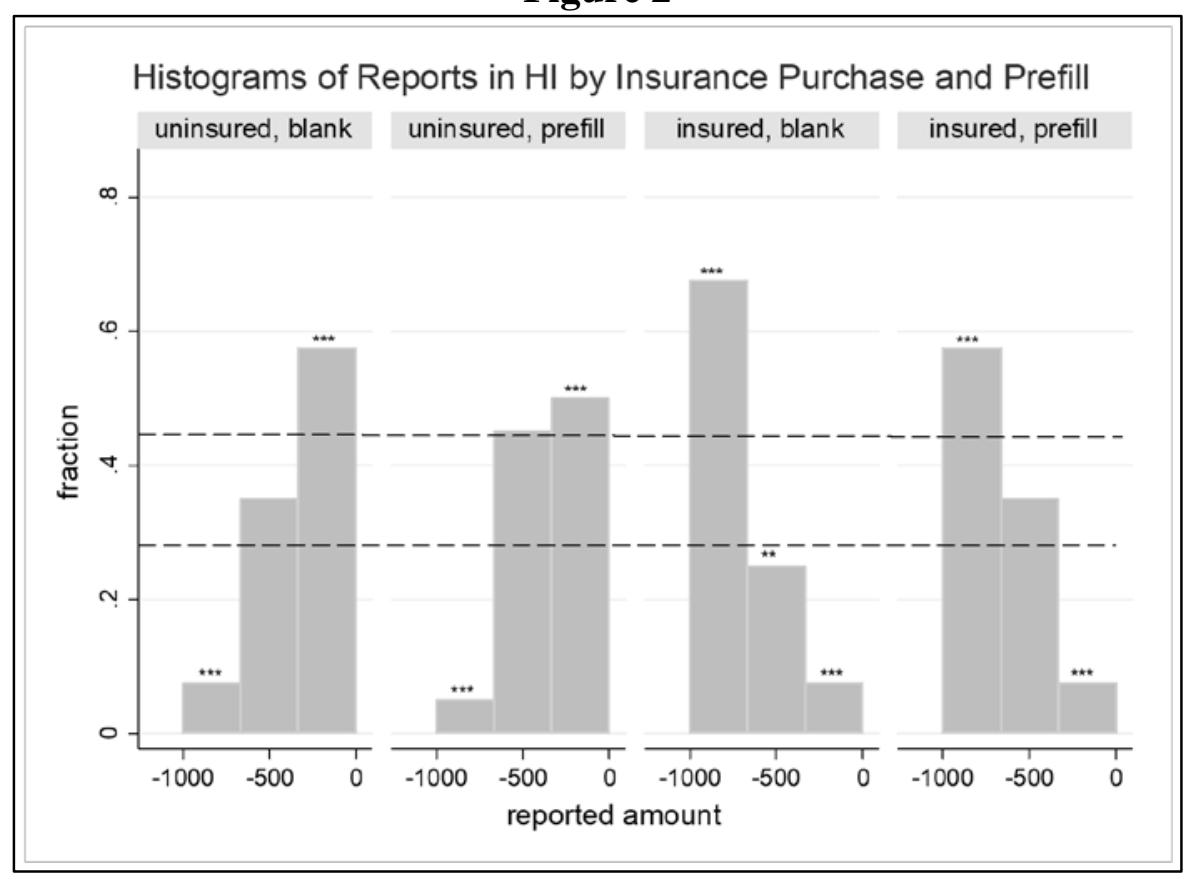

Notes: Histograms of dice outcome reports for HI information asymmetry treatments, by prefill and whether purchased insurance. Two-sided Binomial tests compare observed frequency of report to expected frequency under assumption that everyone reports honestly (dashed lines). $* * *$ observed frequency significantly different from expected at $1 \%$ level; ** significantly different at $5 \%$ level; * significantly different at $10 \%$.

\footnotetext{
${ }^{5}$ Incomplete cheating has become a robust empirical regularity in the experimental cheating literature, dating back to Fischbacher and Föllmi-Heusi's (2013) original die-under-the-cap paradigm. Abeler et al.'s (2019) meta-study covers 72 studies that employ this paradigm and reports that subjects claim only about one-quarter of the payoff-maximizing gains available from cheating.
} 
In all LO treatment outcomes, participants significantly under-report the modal outcome of -500 relative to its expected frequency of $83.3 \%$ and substantially over-report their most favorable outcome (-1000 for the insured and 0 for the uninsured) $(p<.01)$. Participants also under-report their least favorable outcome ( 0 for the insured and -1000 for the uninsured); however, the difference between the observed and expected frequencies is never statistically significant at conventional levels.

Both Table 3 and Figures 2 and 3 suggest that the insured distort their reports to a greater extent than do the uninsured. If we focus solely on the most profitable report, Figures 2 and 3 reveal that the insured report this outcome about 10 and 9 percentage points (hereafter "p.p.”) more often in the HI and LO treatments, respectively, than do the uninsured.

\section{Figure 3}

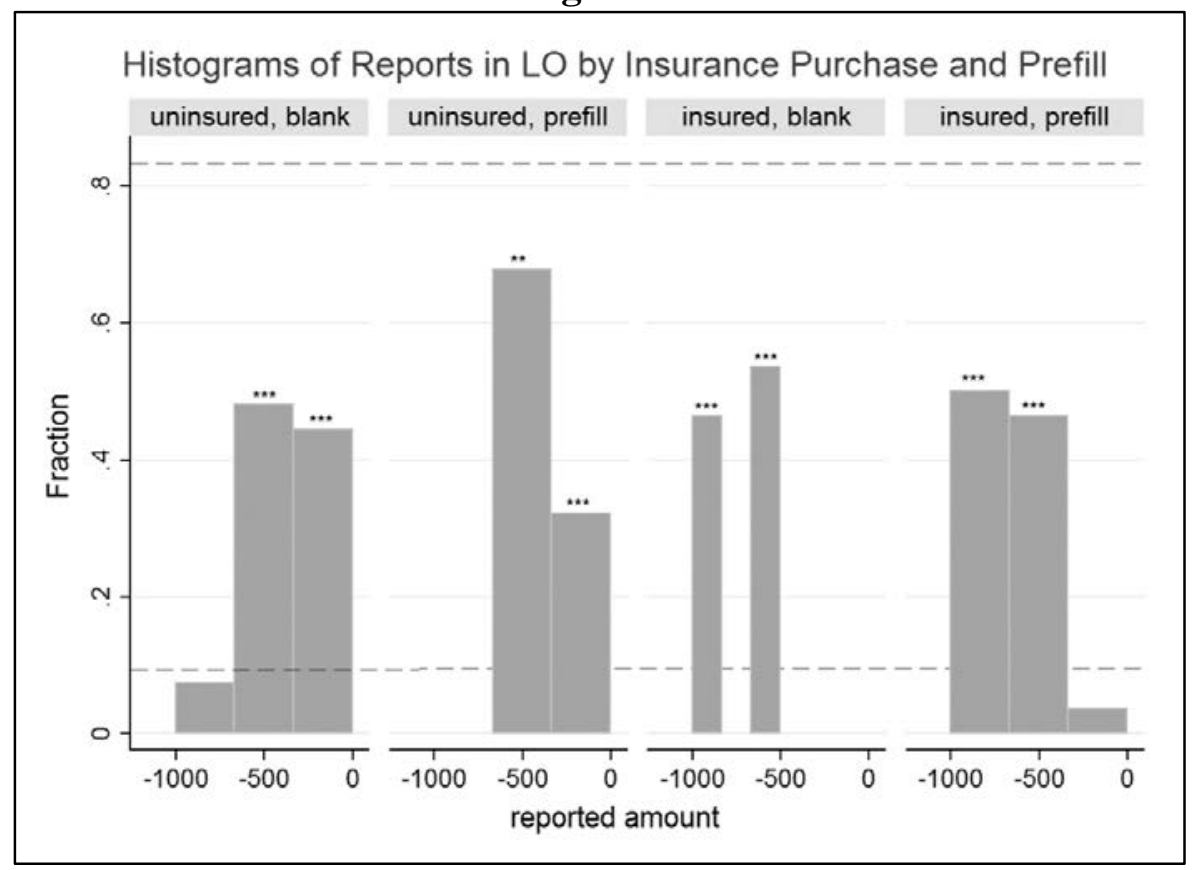

Notes: Histograms of dice outcome reports for LO information asymmetry treatments, by prefill and whether purchased insurance. Asterisks refer to significance levels from two-sided Binomial tests. See Figure 2 Notes.

Following Fischbacher and Föllmi-Heusi (2013), we use the percentage of most profitable reports relative to their expected share to estimate the fraction of maximally dishonest types in each of our sample groups. ${ }^{6}$ Note that for the uninsured all but the most favorable report involves

\footnotetext{
${ }^{6}$ We also estimate the fraction of honest types; however, this calculation relies on those reporting the least favorable outcome of which they are so few that our estimates are highly sensitive to the addition or removal of one or two subjects. Thus, these estimates are to be taken with a grain of salt.
} 
a loss (of either 1000 or 500 lab dollars), whereas these same outcomes for insured subjects offer either a smaller gain than the most favorable report or no gain at all. On this basis, loss aversion predicts a higher percentage of maximally dishonest subjects among the uninsured than the insured. Table 4 displays these percentages among the insured and uninsured in $\mathrm{HI}$ and in LO treatments (combining PREFILL and BLANK).

Table 4: Type Categorization

\begin{tabular}{|l|c|c|c|}
\hline Group & Maximally Dishonest & Honest & Partially Dishonest \\
\hline HI, insured & $48.1 \%$ & $27.0 \%$ & $24.9 \%$ \\
\hline HI, uninsured & $36.0 \%$ & $22.5 \%$ & $41.5 \%$ \\
\hline LO, insured & $43.5 \%$ & $21.4 \%$ & $35.1 \%$ \\
\hline LO, uninsured & $32.6 \%$ & $43.6 \%$ & $23.8 \%$ \\
\hline
\end{tabular}

In both $\mathrm{HI}$ and $\mathrm{LO}$, the percentage of estimated maximally dishonest types is higher among the insured than the uninsured, thereby contradicting loss aversion as an explanation for observed behavior. ${ }^{7}$ Table 4 reveals that the estimated percentage of maximally dishonest insured subjects exceeds that of uninsured subjects by 11 and 12 p.p. in $\mathrm{HI}$ and in LO, respectively.

Selection is another possible explanation for the more dishonest behavior observed among the insured than the uninsured. The dishonesty selection argument proceeds along the following lines: inherently dishonest subjects recognize the opportunity to earn the most by obtaining insurance at a price below $1000 \mathrm{LD}$ and reporting the maximum loss of -1000 LD. To address this selection hypothesis, we asked all subjects, "At which point during Task 2 of the experiment did you decide on which value from the dice outcome to report on the computer screen?” The three available responses were (1) before bidding on the insurance and before rolling the dice; (2) after learning whether I purchased insurance or not, but before rolling the dice; (3) after rolling the dice. If selection accounts for the elevated dishonesty among the insured, then we ought to observe a significantly higher proportion of insured than uninsured who chose (1) as their response. In fact, relatively few subjects in either group indicated that they decided on their report after reading the instructions but before bidding on insurance or rolling the dice (response (1)): only 24/136 (17.7\%) of insured and 17/135 (12.6\%) of uninsured subjects. Rather, in both groups, the overwhelming

\footnotetext{
${ }^{7}$ This result may be regarded as surprising in light of Grolleau et al. (2016) who find that cheating is higher in the loss frame of a real-effort matrix-solving task than an equivalent gain frame when reports are not monitored.
} 
majority wait to see the dice outcome (response (3)) before deciding on their report: 95/136 (69.9\%) of insured and 105/135 (77.8\%) of uninsured subjects. ${ }^{8}$ A chi-square test of proportions cannot reject the equality of the distributions of responses submitted by insured and uninsured subjects $\left(\chi^{2}(2)=2.22, p=.33\right)$. In short, we find no evidence in support of a selection effect, a result confirmed by analysis of an additional treatment (discussed below in section 5) in which participants were not given the opportunity to purchase insurance.

\section{The Role of Pre-filled Fields}

To examine the ability of pre-filled fields to restrain cheating, we return to Figures 2 and 3 in which the PREFILL and BLANK reporting distributions are displayed side-by-side for the uninsured and insured, respectively. Figure 2 attests to the fact that in the HI treatment, the prefilled value of -500 draws subjects to claim this amount at the expense of a more profitable one (namely, 0 for the uninsured and -1000 for the insured). Both for the uninsured and the insured, the shift from the more profitable outcome to the pre-filled value is about 10 p.p. The role of prefilled forms is not so unequivocal in LO. Among the uninsured, the reporting of -500 is almost 50\% higher (20 p.p.) in PREFILL compared to BLANK treatments. This is achieved both by effectively drawing subjects away from the more profitable outcome of 0 , but also by encouraging those who obtained the less favorable outcome of -1000 to instead accept the pre-filled value; no one reports -1000 in this group. At the same time, the PREFILL and BLANK reporting distributions are indistinguishable from one another among the insured $(p=.90)$. Rather than report data on the average insurance premium, the second-to-last column of Table 3 supplies the mean insurance bid by treatment and separately for those who purchased and those who did not purchase insurance. ${ }^{9}$ Notice that the mean bid for insurance for individuals who were successful in receiving it exceeds $1000 \mathrm{LD}$ in all treatments.

\footnotetext{
${ }^{8}$ Evidence that this question captures an intrinsic intention to cheat comes from the observation that the mean report of the 24 insured subjects who chose response (1) is -854 LD, significantly higher than the -737 LD mean report of the 112 insured subjects who decided their report after learning the outcome of the insurance auction or the dice roll (Wilcoxon rank-sum test $\mathrm{p}=.06$ ).

${ }^{9}$ There are two reasons why the magnitude of the insurance premium has not been a significant predictor of reporting behavior thus far. First, as a group-level variable determined by the fifth highest bid, it provides a noisy measure of individual demand for insurance. Second, the premium may have opposite effects on the insured who paid it and the uninsured who were unwilling to pay the price
} 


\section{Regression analysis}

To compare the reports of insured and uninsured, we transform the reporting decision to the selfserving distance from the modal value $(-500)$. Thus, -1000 corresponds to a distance of $500(-500)$ for the insured (uninsured), whereas 0 corresponds to a distance of -500 (500) for the insured (uninsured). A report of -500 corresponds to a distance of zero for both groups. When we regress this distance on an indicator variable for owning insurance (“insured”), regression (1) in Table 5 shows that the coefficient of 46.2 is not quite significant at conventional levels $(p=.13)$. However, the inclusion of treatment controls in (2) augments the coefficient on owning insurance to 59.2 and renders it highly significant $(p=.02)$. In other words, the average report of insured participants is 59 LD more in the direction of profit maximization than that of the uninsured.

Table 5: Regression Results

\begin{tabular}{|c|c|c|c|c|c|}
\hline Variable & $(1)$ & $(2)$ & $(3)$ & (4) & (5) \\
\hline insured & $\begin{array}{c}46.2 \\
(29.5)\end{array}$ & $\begin{array}{l}59.2^{* *} \\
(26.9)\end{array}$ & $\begin{array}{l}57.3^{* *} \\
(26.9)\end{array}$ & & $\begin{array}{c}48.2 \\
(33.0)\end{array}$ \\
\hline PREFILL & & $\begin{array}{l}-27.1 \\
(41.5)\end{array}$ & $\begin{array}{c}-38.9 \\
(39.6)\end{array}$ & $\begin{array}{l}-12.7 \\
(44.2)\end{array}$ & $\begin{array}{l}-25.4 \\
(59.1)\end{array}$ \\
\hline $\mathrm{HI}$ & & $\begin{array}{c}64.5 \\
(52.6) \\
\end{array}$ & $\begin{array}{c}73.7 \\
(51.1)\end{array}$ & $\begin{array}{c}65.9 \\
(51.7) \\
\end{array}$ & \\
\hline HI*insured & & $\begin{array}{c}21.7 \\
(53.3)\end{array}$ & $\begin{array}{l}-43.3 \\
(59.0)\end{array}$ & & \\
\hline HI*PREFILL & & & & $\begin{array}{l}-24.8 \\
(76.7)\end{array}$ & \\
\hline insured*PREFILL & & & & & $\begin{array}{c}-4.1 \\
(59.6) \\
\end{array}$ \\
\hline premium & & & $\begin{array}{l}-0.11 \\
(0.18)\end{array}$ & & \\
\hline risk & & & $\begin{array}{l}0.69 * * \\
(0.26)\end{array}$ & & \\
\hline constant & $\begin{array}{c}211.1^{* * *} \\
(30.08)\end{array}$ & $\begin{array}{c}186.5^{* * *} \\
(38.9)\end{array}$ & $\begin{array}{c}3.4 \\
(126.0) \\
\end{array}$ & $\begin{array}{c}209.1^{* * *} \\
(37.9)\end{array}$ & $\begin{array}{c}223.9 * * * \\
(59.6) \\
\end{array}$ \\
\hline $\mathrm{R}^{2}$ & .006 & .016 & .054 & .010 & .001 \\
\hline $\mathrm{N}$ & 271 & 271 & 268 & 271 & 271 \\
\hline
\end{tabular}

Dependent variable: subject $i$ 's report's self-serving distance from -500 .

Regressors: indicators for whether subjects bought insurance, treatment indicators for "Prefill” and HI information asymmetry and interaction dummies between these variables, the group insurance premium paid, and the investment made in the risky asset in Task 1 . Standard errors are clustered by session.

*** Significant at 1 percent level; ** Significant at 5 percent level; * Significant at 10 percent level.

This gap in reporting behavior between insured and uninsured is robust in magnitude and significance to the addition of two incentivized behavioral measures in (3) also collected over the 
course of our experiment: "premium” is the price of insurance determined by the fifth-price auction in the group of eight; "risk" is the individual amount invested in the risky financial asset in Task 1. The premium variable is not significant. Interestingly, less risk-averse behavior in the investment task predicts submitting a more profitable claim in the reporting task (i.e., more dishonesty), even though individual cheating in the reporting task is undetectable and riskless. To be precise, an additional $30 \mathrm{LD}$ investment in the risky asset is associated claiming 21 more LD (or 21 fewer LD for the uninsured) in the reporting task $(p=.02) .{ }^{10}$ Caution (boldness) in the riskpreferences task is associated with caution (boldness) in the reporting task. A comparison of risk preferences for insured and uninsured participants as revealed by Task 1 shows no significant difference between the two groups $(p=0.32)$.

With regard to the effect of a pre-filled reporting form, regression (3) shows that despite the predicted negative sign on the estimate of the PREFILL indicator of -27.1, the large standard error means that it is not statistically significant $(p=.52)$.

The observed differences in reporting behavior between $\mathrm{HI}$ and $\mathrm{LO}$ as indicated by Table 3 and Figures 2 and 3 suggest that PREFILL may be more effective in HI. Regression (4) allows for this distinction by adding a treatment indicator for $\mathrm{HI}$ and an interaction term between $\mathrm{HI}$ and PREFILL. The estimate on the constant term of 209 implies that on average subjects in the BLANK-LO condition report 209 LD away from -500 in the direction of their most favorable outcome. This deviation is 66 LD larger in BLANK-HI, however the estimate is not significantly different from zero $(p=.22)$. While the negative coefficients on both PREFILL and PREFILL*HI suggest PREFILL may be effective in restraining profitable deviations from -500 , neither one is statistically significant ( $p>.70$ in both cases). Regression (5) permits the PREFILL value to affect the insured and uninsured differently; but neither the estimate of the PREFILL indicator nor its interaction with "insured" differs significantly from zero. We also combined in a single regression (not shown) the HI and insured variables and their interaction terms. While all three PREFILL estimates have the predicted negative sign, none differs significantly from zero.

\footnotetext{
${ }^{10}$ Although not reported in all subsequent regressions, if included, the estimate on "risk" remains right around .70 and is highly significant in all of them.
} 


\section{The absence of an insurance option}

In addition to the sessions in our main experiment as described above, we also ran sessions in which no insurance was available (referred to as NO-INS treatments hereafter). An important reason for doing this is to double check for any evidence of a self-selection effect in the main experiment. As discussed earlier, one might conjecture that the higher observed levels of dishonesty among insured participants follows from a self-selection effect whereby more dishonest types were disproportionately successful in purchasing insurance contracts. If this were the case, we would expect to see significantly more dishonesty among non-insured individuals when no insurance is available relative to uninsured individuals who did not submit high enough bids to receive insurance when it was available.

In addition, without the complications of the insurance market and of formulating a bid in the insurance auction, these NO-INS treatments permit subjects to focus solely on their reporting decision. ${ }^{11}$ All NO-INS treatments were conducted under HI information asymmetry with treatments for pre-filled and blank reporting forms (40 and 43 participants, respectively). Table 6 presents summary results from these treatments.

Table 6: Summary statistics for claims reports among uninsured

\begin{tabular}{|l|c|c|c|}
\hline Treatment & $\begin{array}{c}\text { Mean Report } \\
\text { (Std. Dev.) }\end{array}$ & $\begin{array}{c}\text { \% Report -500 } \\
\text { (Expected) }\end{array}$ & Obs. \\
\hline PREFILL, HI, NO-INS & -300.0 & $\begin{array}{c}40.0 \% \\
(44.4 \%)\end{array}$ & 40 \\
\hline \multirow{2}{*}{ BLANK, HI, NO-INS } & $(335.9)$ & $32.6 \%$ & 43 \\
\hline \multirow{2}{*}{ PREFILL, HI, INS } & -255.8 & $(44.4 \%)$ & 40 \\
\hline \multirow{2}{*}{ BLANK, HI, INS } & -275.0 & $35.6 \%$ & 40 \\
\end{tabular}

Notes: NO-INS refers to sessions in which participants were not offered insurance, while INS refers to groups of participants who remained uninsured after bidding unsuccessfully for an insurance contract.

The summary statistics in Table 6 reveal that NO-INS participants and uninsured participants in the INS treatments report similar die outcomes on average with similar reporting the modal outcome of -500. A Wilcoxon rank-sum test confirms no statistical difference between the

\footnotetext{
${ }^{11}$ While we aimed for session sizes in multiples of eight in all sessions where insurance was available, the absence of the insurance auction granted us additional flexibility to accept fewer or more than eight participants, rather than turn them away with a show-up payment.
} 
distributions of reported values for the two groups ( $p=.89$ ). We therefore conclude that the NOINS group of uninsured participants do not display significantly different levels of dishonesty from the uninsured INS group participants. Consequently, we again find no evidence of a self-selection effect driving the tendency for greater dishonesty among insured participants.

Among the NO-INS group, PREFILL subjects report 44 LD higher losses and fewer of them (seven p.p. less) report the most favorable outcome compared to those in BLANK. However, a rank-sum test of the reporting distributions fails to reject their equivalence ( $p=.50)$ - yet further evidence of the limited ability of prefilled values to restrain cheating.

\section{Conclusions}

Our experiments provide support for the existence of an entitlement effect that leads to significantly greater levels of dishonesty among insured individuals in the reporting of losses for the purpose of reimbursement. Importantly, we present evidence against other potential explanations such as loss aversion, risk aversion and self-selection effects for the observed greater dishonesty among the insured.

In assessing the potential for pre-filled values in reporting forms to discourage dishonesty, the results are less persuasive. The pre-filled value in our experiment exerts only a limited effect on reporting behavior for a number of reasons. First, we estimate that between a third to a half of our participants were maximally dishonest while another substantial fraction reported honestly. To the extent these types are inherent traits, this leaves a relatively small number of moderately dishonest individuals, whose reporting behavior is more likely sensitive to environmental cues such as a pre-populated reporting field. Secondly, the pre-filled value in our reporting form actually promotes dishonesty among those participants whose dice outcomes are even worse than the pre-filled value. For example, an insured individual whose actual die roll payoff is zero and who would have reported this honestly on a blank reporting form may be encouraged to accept a pre-filled value (-500) either through temptation into dishonesty or through mere laziness (default bias). This suggests the importance of choosing a pre-filled value that does not tempt respondents who receive even worse outcomes than the pre-filled amount to simply accept the pre-filled value. Overall, our results suggest that insurance companies should consider strategies and interactions with clients that can lessen the entitlement effects of purchasing insurance. Using an absence of prior claims, tenure as a client or other measures of a valued customer to reward long-standing 
customers who have dutifully paid their insurance premiums may help to weaken the entitlement bias by providing salient benefits to counteract the disutility associated with recurring, uninterrupted premium payments. With respect to pre-filled values, our results suggest caution in insurance claim form applications until more is understood about the sensitivity of reporting behaviour to outcome and reporting distributions and the ability of pre-filled values to influence the behavior of moderately dishonest individuals.

\section{Acknowledgements}

We thank James Amegashie, Jonathan Farrar, Lan Guo, Mary Kelly and participants at the 2019 Canadian Economic Association meetings and 2019 CEAR/MRIC Behavioral Insurance Workshop for valuable suggestions. Chadwick Poon programmed the experiments in oTree. He and Shirish Panchal provided excellent research assistance. Tripat Gill granted us use of his Consumer Research Laboratory at Wilfrid Laurier University and David Cameron helped us run the experiments at McMaster University’s McDSL laboratory. We gratefully acknowledge financial support from the Lazaridis Institute for the Management of Technology Enterprises.

\section{References}

Abeler, Johannes, Daniele Nosenzo and Collin Raymond. (2019) “Preferences for truth-telling,” Econometrica, 87(4), 1115-1153.

von Bieberstein, Frauke, and Jörg Schiller. "Contract design and insurance fraud: an experimental investigation,” Review of Managerial Science 12, 2018, no. 3: 711-736.

Canadian Underwriter. "This percentage of consumers believe auto insurance fraud is an "accepted practice,” May 28 $8^{\text {th }} 2018$, recovered January 31 2019:

https://www.canadianunderwriter.ca/legal/percentage-consumers-believe-auto-insurance-fraud-accepted-practice-1004132273/

Chen, Daniel L., Martin Schonger, and Chris Wickens. "oTree - An open-source platform for laboratory, online, and field experiments," Journal of Behavioral and Experimental Finance, 2016, 9, 88-97.

Cherry, Todd L., Peter Frykblom, and Jason F. Shogren. "Hardnose the dictator." American Economic Review, 2002, 92(4), 1218-1221.

Conners, John and Feldblum S. "Personal Automobile: Cost Drivers, Pricing and Public Policy", Proceedings of the Casualty Actuarial Society, Volume LXXXV, Part 2 No. 163, 1998.

Doxey, Marcus, James Lawson and Shane Stinson. "The Effects of Prefilled Tax Returns on Taxpayer Compliance," unpublished manuscript, 2019.

Duncan, Denvil and Danyang Li. "Liar Liar: Experimental evidence of the effect of confirmationreports on dishonesty,” Southern Economic Journal, 2018, 84(3), 742-770. 
Fischbacher, Urs and Franziska Föllmi-Heusi. "Lies in disguise: An experimental study on cheating,” Journal of the European Economic Association, 2013, 11(3), 525-547.

Fochmann, Martin, Nadja Muller, and Michael Overesch. "Less Cheating? The effects of pre-filled forms on compliance behavior," unpublished manuscript, 2018.

Fonseca, Miguel A. and Shaun B. Grimshaw. "Do behavioral nudges in pre-populated tax forms affect compliance? Experimental evidence with real taxpayers," Journal of Public Policy \& Marketing, 2017, 36(2), 213-226.

García-Gallego, Aurora, Nikolaos Georgantzís, and Ainhoa Jaramillo-Gutiérrez. "Ultimatum salary bargaining with real effort,” Economics Letters, 2008, 98(1), 78-83.

Gillitzer, Christian, and Peer Ebbesen Skov. "The use of third-party information reporting for tax deductions: evidence and implications from charitable deductions in Denmark," Oxford Economic Papers, 2018, 70(3), 892-916.

Gneezy, Uri and Potters, Jan. "An experiment on risk taking and evaluation periods," Quarterly Journal of Economics, 1997, 112 (2), 631-645.

Grolleau, Gilles, Martin G. Kocher, and Angela Sutan. "Cheating and loss aversion: Do people cheat more to avoid a loss?” Management Science, 2016, 62(12), 3428-3438.

Hoffman, Elizabeth, Kevin McCabe, Keith Shachat, and Vernon Smith. "Preferences, property rights, and anonymity in bargaining games." Games and Economic Behavior, 1994, 7(3): 346-380.

Hoffman, Elizabeth and Matthew L. Spitzer. "Entitlements, rights, and fairness: An experimental examination of subjects' concepts of distributive justice,” Journal of Legal Studies, 1985, 14(2), 259-297.

Kleven, Henrik Jacobsen, Martin B. Knudsen, Claus Thustrup Kreiner, Søren Pedersen, and Emmanuel Saez. "Unwilling or unable to cheat? Evidence from a tax audit experiment in Denmark," Econometrica, 2011, 79(3), 651-692.

Kotakorpi, Kaisa, and Jani-Petri Laamanen. "Pre-filled income tax returns and tax compliance: evidence from a natural experiment," University of Tampere, Economics Working Papers, No. 104, (2016).

Mazar, Nina, On Amir, and Dan Ariely. "The dishonesty of honest people: A theory of self-concept maintenance,” Journal of Marketing Research, 2008, 45, no. 6: 633-644.

McGregor, Sue L. T. "Conceptualizing immoral and unethical consumption using neutralization theory,” Family and Consumer Sciences Research Journal 36, 2008, no. 3: 261-276.

Ruffle, Bradley J. "More is better, but fair is fair: Tipping in dictator and ultimatum games," Games and Economic Behavior, 1998, 23(2), 247-265. 
Rumson, Alexander G., and Stephen H. Hallett. "Innovations in the use of data facilitating insurance as a resilience mechanism for coastal flood risk," Science of the Total Environment, 2019, 661, 598-612.

Thomson, Keela S., and Daniel M. Oppenheimer. "Investigating an alternate form of the cognitive reflection test,” Judgment and Decision Making, 2016, 11(1), 99-113.

van Dijk, Wilco, Sjoerd Goslinga, Bart Terwel and Eric van Dijk. "How choice architecture can promote and undermine tax compliance: Testing the effects of prepopulated tax returns and accuracy confirmation," unpublished manuscript, 2020.

Vickrey, William. "Counterspeculation, auctions, and competitive sealed tenders," Journal of Finance, 1961, 16 (1), 8-37. 


\section{Online Appendix A: Participant Instructions}

\section{Introduction}

Welcome and thank you for participating in this experiment in individual decision-making. We ask that you make all decisions on your own without consulting or discussing the experiment with anyone else. At the end of today's session you will be paid a participation fee of $\$ 4$. You are guaranteed to receive this money no matter what. Please take the time to read the instructions carefully. A good understanding of the instructions and well thought out decisions during the experiment can boost the total amount of cash you will receive in addition to your participation fee. Your decisions along with a random factor will determine your total cash payment.

The responses and information you provide in this study will be used anonymously and for research purposes only.

Today's experiment consists of two separate and unrelated decision-making tasks (Task 1 and Task 2) followed by a brief questionnaire.

By completing the two tasks you will earn 'lab dollars' that will be converted into cash at a rate of 70 cents for every 100 lab dollars. Your earnings from the two tasks will be added to your $\$ 4$ participation fee and paid to you at the end of the session.

In a moment the experiment will begin by asking you to read the instructions for Task 1 . You will then be asked to complete Task 1. Next, you will receive another set of instructions for Task 2 and complete Task 2. A short questionnaire will follow. Only after you have completed the questionnaire will you be informed about the outcomes of your decisions in both tasks and your total lab dollars earnings will then be converted into cash and paid to you along with your participation fee and the session will end.

From now until the end of Task 2, we will refer to lab dollar amounts using the term LD. So for example, 500 LD means five hundred lab dollars.

If you have any questions regarding what you have just read, please raise your hand and someone will assist you.

\subsection{Task 1 Instructions}

This task begins with a quiz consisting of 12 questions. Try to answer as many questions correctly as possible in the 6 minutes allotted for the quiz. If you answer fewer than 6 questions correctly, you will not be able to continue to the next portion of Task 1 . If you answer 6 or more questions correctly, you will earn a payment of $300 \mathrm{LD}$ which will be added to your account.

Use of the internet or any electronic device to answer any of the quiz questions is strictly forbidden.

Please click Continue to begin the quiz. When the Continue button is clicked, the quiz begins along with a 'time remaining' window that counts down from 6 minutes to zero. 


\subsection{Task 1 Introduction}

\section{Instructions}

You now have the opportunity to invest all, some or none of the 300 LD you have earned in an investment with two equally likely outcomes: 'success' or 'failure'. Specifically, for any amount of lab dollars you choose to invest, there is a $50 \%$ chance of 'success' and a $50 \%$ chance of 'failure'. If the outcome is 'success', we will pay you 2.5 times the amount you have chosen to invest. However, if the outcome is 'failure', you will lose the amount you invested. You can choose to invest any amount between 0 LD and 300 LD in 30 LD increments. Whatever amount you do not invest will be yours to keep.

Once you have decided how much to invest, the computer will determine 'success' or 'failure' by randomly generating a number between 1 and 100. If the number drawn is greater than 50 the outcome is 'success', but if the number drawn is less than or equal to 50 the outcome is 'failure'.

The table below shows all the possible outcomes and payouts for investing all, some or none of your lab dollars.

\begin{tabular}{|c|c|c|c|c|}
\hline Option & $\begin{array}{c}\text { Amount you } \\
\text { choose to keep }\end{array}$ & $\begin{array}{c}\text { Amount you } \\
\text { choose to invest }\end{array}$ & $\begin{array}{c}\text { Total payment if investment } \\
\text { is a success }\end{array}$ & $\begin{array}{c}\text { Total payment if investment } \\
\text { is a failure }\end{array}$ \\
\hline $\mathbf{0}$ & $300 \mathrm{LD}$ & $0 \mathrm{LD}$ & $300 \mathrm{LD}$ & $300 \mathrm{LD}$ \\
\hline $\mathbf{1}$ & $270 \mathrm{LD}$ & $30 \mathrm{LD}$ & $345 \mathrm{LD}$ & $270 \mathrm{LD}$ \\
\hline $\mathbf{2}$ & $240 \mathrm{LD}$ & $60 \mathrm{LD}$ & $390 \mathrm{LD}$ & $240 \mathrm{LD}$ \\
\hline $\mathbf{3}$ & $210 \mathrm{LD}$ & $90 \mathrm{LD}$ & $435 \mathrm{LD}$ & $180 \mathrm{LD}$ \\
\hline $\mathbf{4}$ & $180 \mathrm{LD}$ & $120 \mathrm{LD}$ & $480 \mathrm{LD}$ & $150 \mathrm{LD}$ \\
\hline $\mathbf{5}$ & $150 \mathrm{LD}$ & $150 \mathrm{LD}$ & $525 \mathrm{LD}$ & $120 \mathrm{LD}$ \\
\hline $\mathbf{6}$ & $120 \mathrm{LD}$ & $180 \mathrm{LD}$ & $570 \mathrm{LD}$ & $90 \mathrm{LD}$ \\
\hline $\mathbf{7}$ & $90 \mathrm{LD}$ & $210 \mathrm{LD}$ & $615 \mathrm{LD}$ & $60 \mathrm{LD}$ \\
\hline $\mathbf{8}$ & $60 \mathrm{LD}$ & $240 \mathrm{LD}$ & $660 \mathrm{LD}$ & $30 \mathrm{LD}$ \\
\hline $\mathbf{9}$ & $30 \mathrm{LD}$ & $270 \mathrm{LD}$ & $705 \mathrm{LD}$ & $0 \mathrm{LD}$ \\
\hline $\mathbf{1 0}$ & $0 \mathrm{LD}$ & $300 \mathrm{LD}$ & $750 \mathrm{LD}$ & \\
\hline
\end{tabular}

Here are two numerical examples with arbitrarily chosen amounts to illustrate how the payments are calculated.

\subsubsection{Example 1}

Suppose you decide to invest 90 LD and keep 210 LD. This means that your lab dollar balance will be 210 LD plus your payout from the investment. There is a 50\% chance that the investment will succeed in which case your $90 \mathrm{LD}$ investment becomes 2.5 x $90 \mathrm{LD}=225 \mathrm{LD}$. Adding this to the $210 \mathrm{LD}$ you kept means that if the investment is successful, you receive a lab dollar balance of $\mathbf{4 3 5} \mathbf{~ L D}$. There is also a 50\% chance your investment will fail, in which case your 90 LD investment will be lost and your lab dollar balance will be the $\mathbf{2 1 0} \mathbf{L D}$ you chose to keep. 


\subsubsection{Example 2}

Suppose you decide to invest 240 LD and keep 60 LD. This means that your lab dollar balance will be 60 LD plus your payout from the investment. The investment will succeed with probability $1 / 2(50 \%)$ in which case your $240 \mathrm{LD}$ investment becomes 2.5 x $240 \mathrm{LD}=600 \mathrm{LD}$. Adding this to the $60 \mathrm{LD}$ you kept means that if the investment is successful you receive a lab dollar balance of $660 \mathbf{~ L D}$. There is also a $50 \%$ chance your investment will fail in which case your 240 LD investment will be lost and your lab dollar balance will be the $60 \mathrm{LD}$ you chose to keep.

If you have any questions about Task 1, please raise your hand and someone will come to assist you.

\subsection{Task 2 Instructions}

This task begins with a quiz consisting of 12 questions. Try to answer as many questions correctly as possible in the 6 minutes allotted for the quiz. If you answer fewer than 6 questions correctly, you will not be able to continue to the next portion of Task 2. If you answer 6 or more questions correctly, you will earn a payment of 1,500 LD which will be added to your account. In the next part of Task 2, you will be asked to make some decisions that will affect the amount of lab dollars in your account.

Use of the internet or any electronic device to answer any of the quiz questions is strictly forbidden.

Please click Continue to begin the quiz. When the Continue button is clicked, the quiz begins along with a 'time remaining' window that counts down from 6 minutes to zero.

\subsection{Task 2 Introduction}

\section{Dice Instructions}

In a few moments, you will be asked to participate in a task where the 'outcome' will be determined by you when you roll the two six-sided dice at your desk. This will be done in private. Only you will see which numbers you roll. You will then report the outcome on your computer screen when prompted.

The sum of the two numbers you roll is a 'dice outcome'. For example, if you roll a 2 and a 6, the dice outcome is 8 . If you roll a 4 and a 5 , the dice outcome is 9 and so on.

In this task, each dice outcome corresponds to one of three possible payoffs involving your lab dollar earnings from Quiz 2:

- A dice outcome of 9, 10, 11 or 12 means you have been assigned a payoff of 0 (no change in your lab dollar balance)

- A dice outcome of 6, 7 or 8 means you have been assigned a payoff of -500 (you lose 500 LD)

- A dice outcome of 2, 3, 4 or 5 means you have been assigned a payoff of -1,000 (you lose 1,000 LD)

Before you roll your two dice, you will have the opportunity to purchase an insurance policy that pays you for any losses you report. If you are successful in purchasing the insurance policy, then the payoff you report will result in you receiving an insurance payment equal to that amount.

- If you have an insurance policy and you report '0', your lab dollar balance will not change. 
- If you have an insurance policy and you report '-500', you will receive an insurance payment of 500 $\mathrm{LD}$ and your lab dollar balance will increase to 2,000 LD.

- If you have an insurance policy and you report '-1,000', you will receive an insurance payment of 1,000 LD and your lab dollar balance will increase to 2,500 LD

The table below shows what happens to your lab dollar balance without and with the insurance policy depending on what you report.

\begin{tabular}{|l|l|l|l|l|}
$\begin{array}{c}\text { What you } \\
\text { report }\end{array}$ & $\begin{array}{c}\text { Dice outcome associated } \\
\text { with this report }\end{array}$ & $\begin{array}{c}\text { Probability of } \\
\text { this happening }\end{array}$ & $\begin{array}{c}\text { Payoff without } \\
\text { insurance }\end{array}$ & $\begin{array}{c}\text { Payoff with insurance } \\
\text { policy }\end{array}$ \\
\hline $0^{\prime}$ & $9,10,11$ or 12 & $10 / 36=27.8 \%$ & No change in your LD & No change in your LD \\
\hline-500 & 6,7 or 8 & $16 / 36=44.4 \%$ & You lose 500 LD & You gain 500 LD \\
\hline-1000 & $2,3,4$ or 5 & $10 / 36=27.8 \%$ & You lose $1,000 \mathrm{LD}$ & You gain $1,000 \mathrm{LD}$ \\
\hline
\end{tabular}

There are a total of 8 participants, including yourself, currently taking part in this experiment. However, only half of you can purchase the insurance policy. This means that 4 of you will receive the insurance policy and 4 will not.

To determine who receives the insurance policy we will sell off 4 policies through an auction. Each of you will be asked to simultaneously enter a lab dollar bid for the right to purchase the insurance policy (up to a maximum of 1,500 LD). The 4 participants who enter the highest bids will receive the insurance policy but will only pay a price equal to the 5th highest bid.

In other words, the 4 highest bidders will purchase the insurance policy at a price equal to the highest rejected bid. If you are successful in purchasing the insurance policy, this price will be deducted from your lab dollar earnings from Quiz 2.

To ensure your understanding, please read through the following hypothetical example:

- Suppose Leslie is one of six individuals bidding in an auction where there are three insurance policies available.

- Also, suppose that Leslie's true valuation of the insurance policy is $800 \mathrm{LD}$ and he bids this amount.

- $\quad$ Now suppose all six bids (including Leslie’s) from highest to lowest are: 


\begin{tabular}{|l|l|l|}
\hline \multirow{2}{*}{ Receive insurance } & Bid 1 & $950 \mathrm{LD}$ \\
\cline { 2 - 3 } & Bid 2 & $800 \mathrm{LD} \leftarrow$ Leslie's Bid \\
\cline { 2 - 3 } & Bid 3 & 650 LD \\
\hline \multirow{2}{*}{ Does not receive insurance } & Bid 5 & 200 LD \\
\cline { 2 - 3 } & Bid 4 & 550 LD $\leftarrow$ The highest losing bid \\
\cline { 2 - 3 } & Bid 6 & 0 LD \\
\hline
\end{tabular}

- The three highest bids are 950 LD, 800 LD and 650 LD which means that Leslie will receive the insurance policy at a price of $550 \mathrm{LD}$, which is $250 \mathrm{LD}$ below Leslie's true valuation.

- The three individuals with the lowest bids do not pay anything and do not receive insurance.

- Notice that if Leslie submits a bid that is lower than his true valuation of the insurance policy, Leslie could lose the opportunity to receive insurance. For example, if Leslie had bid 500 LD, he would not have received insurance.

- So your best strategy is to bid the true value you place on the insurance policy. By bidding your true value, you cannot pay more for the insurance policy than it is worth to you. If you bid less than your true value, you risk not receiving insurance at a price that is below your true value (i.e., a missed opportunity). 


\section{Online Appendix B: Screenshots from the Experiment}

\begin{tabular}{|c|c|c|c|c|}
\hline \multicolumn{5}{|c|}{$\begin{array}{l}\text { Now you must decide how much of your } 300 \text { LD you wish to invest. Choose an amount from the highlighted column in the table } \\
\text { below. }\end{array}$} \\
\hline Option & $\begin{array}{l}\text { Amount you choose } \\
\text { to keep }\end{array}$ & $\begin{array}{l}\text { Amount you choose to } \\
\text { invest }\end{array}$ & $\begin{array}{l}\text { Total payment if investment is } \\
\text { a success }\end{array}$ & $\begin{array}{l}\text { Total payment if investment is } \\
\text { a failure }\end{array}$ \\
\hline 0 & 300 LD & 0 LD & 300 LD & 300 LD \\
\hline 1 & 270 LD & 30 LD & 345 LD & 270 LD \\
\hline 2 & 240 LD & 60 LD & 390 LD & 240 LD \\
\hline 3 & 210 LD & 90 LD & 435 LD & 210 LD \\
\hline 4 & 180 LD & 120 LD & 480 LD & 180 LD \\
\hline 5 & 150 LD & 150 LD & 525 LD & 150 LD \\
\hline 6 & 120 LD & 180 LD & 570 LD & 120 LD \\
\hline 7 & $90 \mathrm{LD}$ & 210 LD & 615 LD & 90 LD \\
\hline 8 & $60 \mathrm{LD}$ & 240 LD & 660 LD & $60 \mathrm{LD}$ \\
\hline 9 & 30 LD & $\mathbf{2 7 0}$ LD & 705 LD & 30 LD \\
\hline 10 & $0 \mathrm{LD}$ & 300 LD & 750 LD & 0 LD \\
\hline Confirm & & & & Show Instructions \\
\hline
\end{tabular}




\section{Dice Outcome Report}

Based on your dice rolls, did you lose 500 LD?

Please either confirm this amount or enter a different amount in the space below. Click the 'Show Instructions' button if you need to recall the payment associated with each dice outcome.

$-500 \quad$ LD

Because you are insured, whatever loss you report will be paid to you. 